\title{
Tinea Gladiatorum Prevalence Among Wrestlers in the Era of Required Skin Inspection
}

\author{
Mark A. Berg (iD) ${ }^{1, *}$, Michael Miner (iD ${ }^{1}$ and William O Roberts (iD) ${ }^{1}$ \\ ${ }^{1}$ Department of Family Medicine and Community, Health University of Minnesota, Minneapolis, MN, USA \\ "Corresponding author: Department of Family Medicine and Community, Health University of Minnesota, Minneapolis, MN, USA. Tel: +1-6512276551, Fax +1-6516512271804,
} Email: bergx004@umn.edu

Received 2020 April 29; Revised 2020 November 01; Accepted 2020 November 04.

\begin{abstract}
Transmittable skin infections in sport are a concern, especially for wrestlers. Current methods for limiting tinea gladiatorum transmission in United States high school wrestling include a required skin inspection protocol. Tinea prevalence before and after the skin inspection protocol was instituted is not widely known. We prospectively determined tinea prevalence among a Minnesota high school wrestler cohort over their 12-week season and compared this to point-in-time incidences reported in wrestlers not subject to a skin inspection protocol. Wrestlers having a suspicious rash at the skin inspection (raised, red, $>5 \mathrm{~mm}$ diameter, and with dry flaky scale) were recruited. Among suspicious rashes, tinea gladiatorum infection was determined using direct microscopy with chlorazol black staining. Thirty-eight of 510 wrestlers (7\%) developed a rash suspicious for tinea. Thirty-four wrestlers that had rash(s) were enrolled and their rash was tested. Twenty-two of 510 wrestlers developed tinea gladiatorum throughout the season. Tinea gladiatorum prevalence was 4.3\% (95\% CI 2.5-6.1\%). Four wrestlers with rash were not available for testing (unable to obtain timely consent (two) or obtain adequate sample(two)). Prevalence was less than suggested by the incidences previously reported in wrestling populations.
\end{abstract}

Keywords: Tinea Gladiatorum, Skin Inspection, Direct Microscopy

\section{Background}

Dermatophytosis is a contagious skin infection. Among wrestlers it is spread primarily through skin to skin contact and is termed "Tinea gladiatorum" (1, 2). Current methods for limiting tinea transmission in United States high school wrestling include a required skin inspection protocol prior to wrestling competition. Tinea gladiatorum prevalence prior to routine skin inspection being conducted is unclear. Published reports include a $24 \%$ incidence among Pennsylvania high school wrestlers (3) surveyed at one point in time. Similarly $24 \%$ of the wrestlers had tinea gladiatorum at a wrestling club in Iran (4). In $2002 \mathrm{Kohl}$ et. al. reported on "tinea gladiatorum: Pennsylvania's experience" and recommended a "prospective analysis" be conducted to better define tinea prevalence and prevention intervention effectiveness (1).

Ashack et. al. retrospectively analyzed data from the National High School Sports-Related Injury Surveillance Study, 2009/2010 through 2013/2014 (5). Tinea gladiatorum prevalence can be calculated at $0.7 \%$ among wrestlers. However, skin inspection for wrestlers was not uniform across the school assigned to surveillance each year. Ath- letes in multiple other sports (boys basketball and football) also developed tinea infections, at lower rates than wrestlers. The authors concluded "(required skin inspection) could reduce infection rates in high school athletics if applied broadly (6).

Since 2009, Minnesota high school wrestlers have undergone a skin inspection protocol prior to Minnesota State High School League (MSHSL) competition. The protocol was developed by the National Federation of High Schools (5). The protocol states that wrestlers found to have a rash at skin inspections be withheld from competition until they present the MSHSL Skin Condition Report which indicates that the rash is either non-contagious or has received adequate treatment.

\section{Objectives}

Prospectively determine tinea gladiatorum prevalence among a Minnesota high school wrestling cohort. The cohort is geographically defined and followed over the 12week season. Tinea prevalence observed is compared to the 
tinea incidence reported prior to the initiation of the required skin inspection protocol.

\section{Methods}

In the fall of 2017, the investigator emailed coaches and administration from nineteen adjacent high schools in the St. Paul and surrounding area. Information on the study was disclosed. Seventeen of the nineteen high schools agreed to participate. Permission to conduct the study was obtained through each school district. The study protocol conforms to the ethical guidelines of the 1975 Declaration of Helsinki. The study was approved by the University of Minnesota IRB \#STUDY00001578.

During the wrestling season (November 20th, 2017 February 11th, 2018), wrestlers underwent the MSHSL required skin inspection prior to each competition. Competitions occurred 1-2 times per week. Inspections followed the protocol established by the National Federation of High Schools (5). The head wrestling coach contacted the principal investigator when a wrestler with a rash suspicious for tinea (raised, red, > $5 \mathrm{~mm}$ diameter, and with dry flaky scale) was identified at the inspection.

Parent(s) of wrestlers with the rash that met inclusion criteria were contacted by the principal investigator and the study was explained. Parent(s) and wrestlers choosing to participate gave informed consent and were enrolled in the study. The rash was sampled by the principal investigator or research associate within 24 hours of being reported.

Direct microscopy was selected for tinea diagnosis because of it's high sensitivity (7). The rashes' leading edge was gently scraped with a \#15 blade to obtain a keratinocyte sample. The sample was fixed on a glass microscope slide. Chlorazol black stain, which combines chlorazol black E (stains tinea elements green), potassium hydroxide (breaks down non-tinea keratin and cells) and dimethylsulfoxide (accelerates the process), was applied. The slides were read by a board certified Dermatopathogist for the presence (positive result) or absence (negative result) of tinea gladiatorum.

\section{Results}

The 19 high school teams initially contacted had 544 members. The 17 high school teams monitored had 510 members. We monitored 510 of 544 (93\%) high school wrestlers within the geographical area.

During the season, 38 of the 510 wrestlers (7\%) had identified at skin inspection a rash that met inclusion criteria and were reported to the Investigator. Consent was able to be obtained from 34 wrestlers and their rashes were tested. We were unable to obtain timely consent from two wrestlers. We were unable to obtain timely adequate samples from two wrestlers. A total of four wrestlers with rash were not tested. Figure 1 details participant screening, enrollment and results.

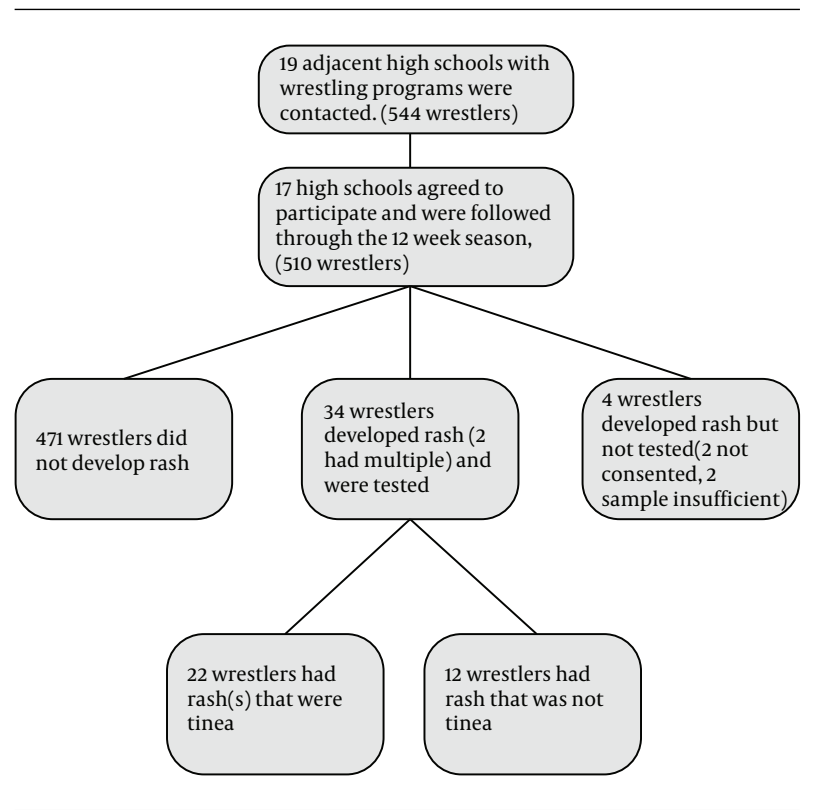

Figure 1. Enrollment Flow Chart

Throughout the 12 week season, twenty-two of the 510 wrestlers developed direct microscopy confirmed tinea. Tinea gladiatorum prevalence was 4.3\% (95\% CI 2.5-6.1\%).

Two consented wrestlers developed another rash at new sites during the season. A total of 36 rashes were tested. Twenty-three (64\%) were direct microscopy positive for tinea. Table 1 details rashes that developed at the seventeen high schools and direct microscopy results.

\section{Discussion}

Prior tinea gladiatorum studies surveyed the incidence of rash at one point in time. We prospectively observed a population of wrestlers over time. The overall prevalence of rash over the twelve-week season was less than expected based on published studies of an Iranian wrestling club and wrestlers at a Pennsylvania high school. Both these groups were evaluated at places and times that did not include a skin inspection protocol which removed wrestlers with rash from competition.

The lower $4.3 \%$ prevalence we found compared with previously reported $24 \%$ incidence may be explained by the effectiveness of the required skin inspection prior to each competition protocol. Other factors may include the 


\begin{tabular}{|c|c|c|c|}
\hline High School & No. of Wrestlers that Developed Rash and Were Studied (No. Not Studied) & Positive Direct Microscopy & Negative Direct Microscopy \\
\hline $\mathbf{1}$ & 0 & 0 & 0 \\
\hline 2 & 0 & 0 & 0 \\
\hline 3 & 1 & 0 & 1 \\
\hline 4 & 0 & 0 & 0 \\
\hline 5 & 1 & 1 & 0 \\
\hline 6 & $4(2)$ & 1 & 3 \\
\hline 7 & $12(2)$ & 8 & 4 \\
\hline 8 & 1 & 1 & 0 \\
\hline 9 & 3 & 1 & 2 \\
\hline 10 & 0 & 0 & 0 \\
\hline 11 & 0 & 0 & 0 \\
\hline 12 & 3 & 3 & 0 \\
\hline 13 & 1 & 1 & 0 \\
\hline 14 & 0 & 0 & 0 \\
\hline 15 & 3 & 2 & 1 \\
\hline 16 & 0 & 0 & 0 \\
\hline 17 & 5 & 4 & 1 \\
\hline Total & $34(4)$ & 22 & 12 \\
\hline
\end{tabular}

geographical location of Minnesota (cold, lower humidity winters). Prevalence can vary depending on geographical region (7).

Thirty-six percent of the rashes that were visually suspicious for tinea were direct microscopy negative. Nummular eczema, pityriasis roseola, granuloma annulare and other conditions can mimic tinea. Confirmatory testing is important for accurate diagnosis.

Study limitations include the previously reported incidences of $24 \%$ wrestlers having tinea gladiatorum were likely surveyed during an outbreak. Seven percent of the high school wrestlers in the geographical region we followed competed on the two high schools that were not monitored. Also four wrestlers being monitored developed rashes that were not tested. Assuming all four rashes were tinea, the highest prevalence would have been 26 out 510 wrestlers (5.0\%) developing tinea. Hygiene elements like wrestling mat sanitization, skin wipes, washing by wrestlers, and pretreatment with barrier foam prior to exposure are felt to be important preventative methods. These were assumed to be fairly uniform throughout our study population.

Accurate tinea prevalence reporting will facilitate future preventative study planning. Preventative methods effective in wrestling can be applied to other sports with risks for transmittable skin infections.

\section{Acknowledgments}

The authors thank Dr. Daniel Miller, University of Minnesota Dermatopathology for performing the direct microscopy. The authors thank research associates Matthew Runde DO and Jami Weber DO.

\section{Footnotes}

Authors' Contribution: Author Contributions: Study concept and design: M.B., M.M. and W.R.; analysis and interpretation of data: M.B and M.M.; drafting of the manuscript: M.B. and W.R.; critical revision of the manuscript for important intellectual content: M.B., M.M and W.R.; statistical analysis: M,M.

Conflict of Interests: None declared.

Ethical Approval: The study was approved by the University of Minnesota IRB \#STUDY00001578.

Funding/Support: JNC Corp. of Tokyo, Japan sponsored the study with a grant of $\$ 15,145.00$.

Informed Consent: Parent(s) and wrestlers choosing to participate gave informed consent and were enrolled in the study. 


\section{References}

1. Kohl TD, Giesen DP, Moyer JJ, Lisney M. Tinea gladiatorum: Pennsylvania's experience. Clin J Sport Med. 2002;12(3):165-71. doi: 10.1097/00042752-200205000-00004. [PubMed: 12011724].

2. Anderson BJ. Skin Infections in Minnesota High School State Tournament Wrestlers: 1997-2006. Clinical Journal of Sport Medicine. 2007;17(6):478-80. doi: 10.1097/JSM.0b013e31815ac43d.

3. Adams BB. Tinea corporis gladiatorum: a cross-sectional study. $J$ Am Acad Dermatol. 2000;43(6):1039-41. doi:10.1067/mjd.2000.109284. [PubMed: 11100020].

4. Ahmadinejad Z, Razaghi A, Noori A, Hashemi SJ, Asghari R, Ziaee V. Prevalence of fungal skin infections in Iranian wrestlers. Asian
J Sports Med. 2013;4(1):29-33. [PubMed: 23785573]. [PubMed Central: PMC3685157].

5. Sieck B. Pre-match requirements for referees clarified in high school wrestling. 2020, [cited February 17th]. Available from: https://www.nfhs.org/articles/pre-match-requirements-forreferees-clarified-in-high-school-wrestling/.

6. Ashack KA, Burton KA, Johnson TR, Currie DW, Comstock RD, Dellavalle RP. Skin infections among US high school athletes: A national survey. J Am Acad Dermatol. 2016;74(4):679-84 e1. doi: 10.1016/j.jaad.2015.10.042. [PubMed: 26850656].

7. Ebrahimi M, Zarrinfar H, Naseri A, Najafzadeh MJ, Fata A, Parian M, et al. Epidemiology of dermatophytosis in northeastern Iran; A subtropical region. Curr Med Mycol. 2019;5(2):16-21. doi:10.18502/cmm.5.2.1156. [PubMed: 31321333]. [PubMed Central: PMC6626711]. 